\title{
Drug injection to sites other than arm: a study of Iranian heroin injectors
}

\author{
Mehrdad Karimi ${ }^{1}$, Hafez Ghaheri ${ }^{2}$, Shervin Assari ${ }^{3}$, Khodabakhsh Ahmadi ${ }^{4}$, Maryam Moghani Lankarani ${ }^{5}$, \\ Reza Moghani Lankarani ${ }^{6}$, Hooman Narenjiha $^{7}$, Hassan Rafiey ${ }^{7}$, Mahmood Tavakoli ${ }^{7}$ and Firoozeh Jafari $^{7}$ \\ 1 Shahrekord University of Medical Sciences, Tehran, Iran \\ 2 Isfahan University of Medical Sciences, Isfahan, Iran \\ ${ }^{3}$ Department of Health Behavior and Health Education, University of Michigan School of Public Health, Ann Arbor, MI, USA \\ ${ }^{4}$ Behavioral Sciences Research Center, Baqiyatallah Medical Sciences University, Tehran, Iran \\ ${ }^{5}$ Universal Network for Health Information Dissemination and Exchange, Tehran, Iran \\ ${ }^{6}$ Medicine and Health Promotion Institute, Tehran, Iran \\ 7 Substance Abuse and Dependence Research Center, University of Social Welfare and Rehabilitation Sciences, Tehran, Iran
}

\section{Edited by:}

Mohammadreza Mokhtari, Institute of

Living - Hartford Hospital, USA

\section{Reviewed by:}

Angelo Giovanni Icro Maremmani,

University of Pisa, Italy

Mohammadreza Mokhtari, Institute of

Living - Hartford Hospital, USA

Masoumeh Dejman, University of

Social Welfare and Rehabilitation

Sciences, Iran

\section{*Correspondence:}

Mahmood Tavakoli, Substance Abuse and Dependence Research Center, University of Social Welfare and

Rehabilitation Sciences, Koodak-yar Ave Daneshjoo Blvd., Evin Tehran, Iran e-mail: tavackoli@hotmail.com
For almost all injecting drug users (IDUs), the first site of injection is the arm. Years after injection, IDUs may shift to using other sites for intravenous (IV) access. Although injection to sites other than the arm is associated with higher risks, literature is limited regarding this behavior. We aimed to determine the prevalence and associated factors of using IV access points other than the arm among a national sample of IDUs in Iran. Data came from the National Drug Dependence Survey, 2007, which had enrolled 863 IDUs with at least one daily injection. Data on socio-demographics, pattern of drug use, and injection-related behaviors were entered into a logistic regression to determine predictors of injection to sites other than the arm. From all participants, 54.8\% reported current injection sites in areas other than the arm. The other injection sites were the femoral venous sinus (17.0\%), followed by the groin (14.5\%) and neck (11.5\%). Logistic regression revealed that living alone [odds ratio $(\mathrm{OR})=1.789,95 \%$ confidence interval $(\mathrm{Cl})=1.218-2.629]$, being Sunni $(\mathrm{OR}=3.475,95 \% \mathrm{Cl}=1.775-6.801)$, having higher family income $(O R=1.002,95 \% \mathrm{Cl}=1.001-1.003)$, higher age at first drug use $(O R=1.039,95 \%$ $\mathrm{Cl}=1.009-1.069)$, longer injection duration $(\mathrm{OR}=1.071,95 \% \mathrm{Cl}=1.041-1.102)$, and more injection frequency $(\mathrm{OR}=1.255,95 \% \mathrm{Cl}=1.072-1.471)$ were associated with higher likelihood of using injection sites other than the arm. Using sites other than the arm for IV injection is linked to socio-demographics, drug use data, and injection-related characteristics that can be used by policy makers. This information can be used for harm reduction planning.

Keywords: drug injection, injection sites, arm, Iran, heroin

\section{INTRODUCTION}

Intravenous (IV) access points can develop several local complications that may involve skin or vascular structure (1-9). These complications vary in severity from a simple erythema and pain, to necrosis, thrombophlebitis, vein sclerosis, and occlusion. Following these complications, injecting drug users (IDUs) show interest in using other IV access points from an unusable vein to a new useable one $(10,11)$. Detailed information on IV access points increases our knowledge about IDUs' high-risk behaviors. Clinicians, public health practitioners, and policy makers may use such information to protect the health of IDUs.

Although we know that first injections often begin in the arm as the primary point for IV access (10), there is lack of knowledge on trajectory of IDUs in using different IV access points. According to the current literature, most IDUs begin their injecting practice using the arm and then gradually shift to other sites including forearm, upper arm, hand, neck, feet, leg, and femoral vein. Some researchers regard IV access point as a measure of the severity of problems of IDUs (11).
The purpose of this study was to determine prevalence and associated factors of non-arm injection among Iranian IDUs using heroin.

\section{MATERIALS AND METHODS DESIGN AND SETTING}

Data came from the National Drug Dependence Survey that was conducted in 2007 and used a cross-sectional design. The main survey had a sample size of 7,743 performed by the research center for substance abuse and dependence at the University of Social Welfare and Rehabilitation Sciences. Some other manuscripts have been published from this database $(12,13)$.

\section{PARTICIPANTS AND SAMPLING}

The participants were substance-dependent adults according to the DSM-IV. Participants were sampled from treatment centers $(n=1,217)$, prisons $(n=584)$, or streets $(n=5,860)$ from the capitals of 29 provinces in Iran. The sampling strategy in treatment centers and prisons was random, but snowball in streets. 
The number of samples taken from every province was proportional to the population of the province. The sampling started in April 2007 and lasted for 5 months.

\section{PROCESS}

The interviews were carried out by university graduates (MS, BS) with drug abuse-related majors/degrees who were dispatched to the provinces after being trained through workshops in Tehran (the capital of the Islamic Republic of Iran). Each interview took 60-90 min. Data were collected using a paper-based questionnaire that was the modified version of the one used in the previous national survey in Iran (14). The questionnaire included 69 items in nine sections.

\section{SECONDARY ANALYSIS}

This study used a sample of all 863 IDUs with at least once daily heroin injections for 1 year. Participants were all heroin users with at least once daily heroin injections. We entered the following data into our analysis: socio-economic data, drug use pattern, and injection-related data.

\section{OUTCOME}

"Injection to other sites than arm" was determined by the following question: To which site do you often inject? Responses included the femoral venous sinus, groin, neck, and other sites.

\section{CODES OF ETHICS}

The study was approved by the ethical review committee of the University of Social Welfare and Rehabilitation Sciences. Informed consent was obtained from all the participants after they had been verbally reassured that the information would be kept confidential, especially from the correctional system.

\section{STATISTICAL ANALYSIS}

Data were analyzed in the SPSS for Windows 13 statistical package. Continuous variables were described using mean and standard deviation (SD) or median (percentile 25\%=Q1 and percentile $75 \%=\mathrm{Q} 3$ ). In order to determine the association between independent variables and outcome (injection to sites other than the arm), the $\chi^{2}$ test, independent samples $t$ test and Mann-Whitney were used. Logistic regression was used for multivariable analysis. Odds ratios (ORs), with 95\% confidence intervals (CIs) were reported. $P$-value $<0.05$ was considered significant.

\section{RESULTS}

DEMOGRAPHICS AND DRUG-RELATED DATA

From the total 863 IDUs who were enrolled into this study, most participants were mostly men, Muslim, and had started drug use with opioids (Table 1).

Participants had a mean age of $31.7 \pm 8.6$ years. First drug use and injection had begun at $18.1 \pm 5.3$ and $25.7 \pm 6.6$, respectively. Injection duration was $6.0 \pm 5.9$ years. Mean income and drug payment were US \$ 306.0 (835.3) and US \$ 218.9 (300.5), respectively.
Table 1 | Socio-demographic, drug related, and drug problems among IDUs $(n=863)$.

\begin{tabular}{lrr}
\hline & $\boldsymbol{n}$ & $\%$ \\
\hline SAMPLING PLACE & & \\
Street & 693 & 80.3 \\
Prison & 59 & 6.8 \\
Treatment centers & 101 & 11.7 \\
Missed & 10 & 1.2 \\
SAMPLING PROVINCE & & \\
Tehran & 206 & 23.9 \\
Khorasan & 66 & 7.6 \\
Guilan & 63 & 7.3 \\
Yazd & 61 & 7.1 \\
Lorestan & 48 & 5.6 \\
Hamedan & 40 & 4.6 \\
Kordestan & 35 & 4.1 \\
Fars & 34 & 3.9 \\
Hormozgan & 32 & 3.7 \\
Others & 278 & 32.2 \\
SOCIO-DEMOGAPHI
\end{tabular}

\section{SOCIO-DEMOGRAPHIC DATA}

Gender

Men

Women

Missed

Religion

Islam

32.2

Shia

Sunni

Other religions

Missed

Unemployed

Employed

Missed

Living alone

$\begin{array}{lll}\text { With others } & 688 & 79.7\end{array}$

$\begin{array}{lll}\text { Alone } & 175 & 20.3\end{array}$

Missed

0

0

DRUG USE DATA

First drug of abuse

Cannabis 289

Opium or its derivates 296

Heroin

Amphetamines

96.8

25

2.9

0.3

Others

98.4

92.4

6.0

Current dominant drug

Powder heroin

Crystal heroin

Years injection

$1-4$

5-9

10-14

15-19

20 and more

Monthly injection frequency

3 times or less

4-30 times

31-60 times

61-90 times

90 times or more

\section{8 7

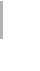


Table 2 | Regressors of non-arm injection among Iranian IDUs ( $n=863$ ).

\begin{tabular}{|c|c|c|c|c|c|c|c|c|}
\hline \multirow[t]{2}{*}{ Characteristics } & \multirow[t]{2}{*}{$B$} & \multirow[t]{2}{*}{ SE } & \multirow[t]{2}{*}{ Wald } & \multirow[t]{2}{*}{ df } & \multirow[t]{2}{*}{ Sig. } & \multirow[t]{2}{*}{$\operatorname{Exp}(B)$} & \multicolumn{2}{|c|}{$95 \% \mathrm{Cl}$ for $\operatorname{EXP}(B)$} \\
\hline & & & & & & & Lower & Upper \\
\hline Living status (alone) & 0.582 & 0.196 & 8.781 & 1 & 0.003 & 1.789 & 1.218 & 2.629 \\
\hline Islam type (Sunni) & 1.245 & 0.343 & 13.210 & 1 & 0.000 & 3.475 & 1.775 & 6.801 \\
\hline Family income (\$ US) & 0.001 & 0.000 & 7.367 & 1 & 0.007 & 1.001 & 1.000 & 1.001 \\
\hline Age at first use (years) & 0.038 & 0.015 & 6.572 & 1 & 0.010 & 1.039 & 1.009 & 1.069 \\
\hline Injection duration (years) & 0.069 & 0.014 & 22.713 & 1 & $<0.001$ & 1.071 & 1.041 & 1.102 \\
\hline Past year injection frequency & 0.227 & 0.081 & 7.939 & 1 & 0.005 & 1.255 & 1.072 & 1.471 \\
\hline
\end{tabular}

\section{INJECTION TO OTHER SITES}

Sites other than the arm were reported to be the site of injection among $54.8 \%$ of IDUs $(n=473)$. Injection sites included the groin $(n=125 ; 14.5 \%)$, neck $(n=99 ; 11.5 \%)$, femoral venous sinus $(n=147 ; 17.0 \%)$, and others $(n=26,3.0 \%)$.

Based on our bivariate analysis, being Sunni $(\mathrm{OR}=1.406,95 \%$ $\mathrm{CI}=1.187-1.667)$ and living alone $(\mathrm{OR}=1.218,95 \% \mathrm{CI}=1.057-$ 1.403 ) were associated with higher likelihood of non-arm injection. Although men had a higher rate of non-arm injection than women, this difference was not significant $(\mathrm{OR}=1.540,95 \%$ $\mathrm{CI}=0.910-2.607)$.

Logistic regression revealed that living alone $(\mathrm{OR}=1.789,95 \%$ $\mathrm{CI}=1.218-2.629)$, being Sunni $(\mathrm{OR}=3.475$, 95\% CI $=1.775-$ 6.801), higher family income $(\mathrm{OR}=1.002,95 \% \mathrm{CI}=1.001-$ $1.003)$, higher age at first use $(\mathrm{OR}=1.039,95 \% \mathrm{CI}=1.009-1.069)$, longer injection duration $(\mathrm{OR}=1.071,95 \% \mathrm{CI}=1.041-1.102)$, and more injection frequency $(\mathrm{OR}=1.255,95 \% \mathrm{CI}=1.072-$ 1.471) were associated with an increased likelihood of injection to IV access points other than the arm (Table 2).

\section{DISCUSSION}

More than half of Iranian male IDUs use IV access points other than the arm. Logistic regression revealed that likelihood of other IV access points other than the arm was increased by some socio-economic characteristics such as living alone $(\mathrm{OR}=1.789)$, being Sunni (OR=3.475), and higher family income (\$ US) $(\mathrm{OR}=1.002)$. Drug-related data such as higher age at first drug use $(\mathrm{OR}=1.039)$, and injection-related data such as more injection duration $(\mathrm{OR}=1.071)$ and injection frequency $(\mathrm{OR}=1.255)$ were also linked to this behavior.

From the above list of factors, the effect of injection duration and injection frequency on likelihood of shifting to other sites of injection was expected, as shift in IV access point occurs as drug injection progresses. That is, the shift in site of drug use may be a part of the natural history of drug injection. However, in the very limited pool of published evidences about pattern of IV access points, we could not find any evidence confirming or rejecting our findings about the association of being Sunni, family income, age at first drug use, or our outcome.

In contrast to our expectations, and opposite to the literature that emphasizes the role of low socio-economic status as a risk factor of poor health (15-18) and health risk behaviors $(19,20)$, our study suggested that IDUs with higher family income may be at higher risk of shifting to using other IV access points.
Different from most of the literature, it was not lower age at first drug use $(21,22)$ but higher age at first drug use that was associated with higher risk of shifting from the arm to another injection site. Similar to our findings, one study on 144 IDUs with $\leq 5$ years of injection use reported that adolescentinitiating IDUs were less likely to report high-risk sex and injection behaviors than adult-initiating IDUs (23). Baldwin et al. (24) reviewed the literature and hypothesized that early initiation of substance use may be associated with a pattern of maladaptive coping mechanisms in which the substance is implemented to manage stress (25). Heavy drug use, during a critical period of neurobiological development, may also lead to dysfunction in memory and learning, inhibition, and executive functioning and neuronal activation, or even ultimately alterations in brain structure (26).

The use of injection sites other than the arm among IDUs is a major public health concern. Such behaviors are often associated with an increased risk of vascular complications such as deep vein thrombosis, leg ulcers, and vascular insufficiency. In addition, in some sites such as the groin and neck, the close proximity to other organs poses the risk of inadvertent trauma to these sites (27). Unfortunately, data is systematically scarce in this regard (10).

Some years after first injection (10), IDUs may have some concerns about difficulty of injection in previous injection sites, and worry about the risk of loss of the injection/hit. In this stage, other sites might be seen by an IDU as "easy-to-use" with more secure delivering of the injection intravenously (10). An IDU may show interest in using other points for IV access, as a result (11).

Within non-arm injection sites, the most frequent site was the groin. According to the literature, among heroin IDUs, groin injection seems convenient, providing quick access, with little mess and less pain than smaller more awkward veins. The formation of sinuses over time facilitates continued use of the groin (10).

According to our findings, likelihood of non-arm injection increases by an increase in injection duration. Literature confirms that most IDUs begin to use other injection sites years after their first injection (10). According to a study, IDUs shift to injection in the forearm in 2 years, shift to injection in the upper arm in 3.5 years, shift to injection in the hand, neck, feet, and leg in 4 years, and shift to injection in the groin 10 years after their first injection (11). Injectors decide to shift to a new injection site when they believe the previous site is no longer accessible (10). 
Based on harm reduction protocols, practices such as the rotation of injecting sites may prevent scar tissue occlusion, swelling, infections, and deep vein thrombosis among IDUs. In addition, literature cites that IDUs believe that this rotation is both difficult and unreliable. The rotation of injecting to both arms needs using non-dominant hands, which might seem problematic to IDUs. Secondary to this perceived difficulty, IDUs find other IV access points as convenient, providing quick access, with little mess and less pain than previously used arm veins (10).

Non-arm injection is of interest because it is linked to high rates of local complications including tissue damage, infections, and deep venous thrombosis $(10,11)$. Our recommendation to service providers is that site of injection is an important factor that should be asked about when a service is being delivered to an IDU. Harm reduction services in Iran should include safe injecting trainings for IDUs.

This study sheds more light on the risk factors of transition to more severe injection sites. Of the factors, injection frequency and living status are modifiable, and can be considered as the target of prevention programs. Injecting to sites such as the femur or neck should be strongly discouraged, because of the associated health hazards. These veins are at proximity of vital arteries. Missing the aimed vein may result in hitting the artery or nerves, which may cause major health problems for the IDU $(28,29)$. Promotion of safe injection should be considered as a part of harm education programs, and may encourage the practice of safe injection among IDUs. Such training programs can be delivered as a part of needle exchange programs.

Safe injecting education programs may benefit from information about the motivations for transitioning to new IV access points. We do not know whether training programs that enhance safe injection information among IDUs will increase the use of peripheral veins and decrease the use of risky injection sites such as neck and groin. IDUs should not be encouraged to use others for injection or injection facilitation, as presence of other IDUs at the time of injection may increase the risk of shared injection, which is linked to risk of blood-borne infections such as HIV. However, IDUs should receive information on health risks associated with transition to other access points for injections.

Not only may the findings of this research be of interest to the policy makers in Iran, but they may also benefit the global harm reduction community. Groin injecting is a neglected topic. Similar studies will shed more light on factors that are linked to similar practices among IDUs. Information provided by this study is hoped to be used for the development of evidence-based safe injecting advice.

\section{LIMITATION}

Although Iran is a country that includes multiple ethnicities with unique cultures, we did not enter ethnicity to our analysis. Some participants were sampled using a snowball strategy, thus the results are not generalizable to all Iranian male IDUs. This study did not enquire data on the pattern of transition between different injection sites. The study only included heroin users, thus further research is needed on individuals who inject drugs other than heroin. This study had a retrospective design. Longitudinal studies are still required. Further work is needed to better understand the natural history of IDUs, especially their pattern of shift in IV access points.

\section{CONCLUSION}

This study found that half of Iranian male IDUs report injection to IV accesses points other than the arm. This behavior is attached to some socio-economic and drug-related characteristics. Information on factors associated with non-arm injection may be used for evidence-based harm reduction practice.

\section{ACKNOWLEDGMENT}

We would like to thank Aurora Turek for her contribution to the draft of this paper.

\section{REFERENCES}

1. Milloy MJ, Wood E, Lloyd-Smith E, Grafstein E, Tyndall M, Montaner J, et al. Recent incarceration linked to cutaneous injection-related infections among active injection drug users in a Canadian setting. J Community Health (2010) 35(6):660-6. doi:10.1007/s10900-010-9269-y

2. Ho RC, Ho EC, Mak A. Cutaneous complications among i.v. buprenorphine users. J Dermatol (2009) 36(1):22-9. doi:10.1111/j.1346-8138.2008.00581.x

3. Pfefferkorn U, Viehl CT, Bassetti S, Wolff T, Oertli D. Injection site abscesses in intravenous drug users. Frequency of associated complications related to localisation. Chirurg (2005) 76(11):1053-7. doi:10.1007/s00104-005-1042-x

4. Del Giudice P. Cutaneous complications of intravenous drug abuse. Br J Dermatol (2004) 150(1):1-10. doi:10.1111/j.1365-2133.2004.05607.x

5. Hengge UR, Beiderlinden M, Otterbach F, Groeben H, Nast-Kolb D, Mehnert WH, et al. 31-year-old injection drug user with massive skin necrosis and shock. Dermatology (2003) 206(2):169-71. doi:10.1159/000068458

6. Cagle HH, Fisher DG, Senter TP, Thurmond RD, et al. Classifying Skin Lesions of Injection Drug Users: A Method for Corroborating Disease Risk. Rockville, MD: Department of Health and Human Services (2002).

7. Horowitz HW. Learning to recognize scarring among intravenous drug users: a tool for HIV risk reduction. Am J Public Health (1997) 87(7):1233-4. doi:10.2105/AJPH.87.7.1233

8. Cherubin C, Sapira JD. The medical complications of drug addiction and the medical assessment of the intravenous drug user: 25 years later. Ann Intern Med (1993) 119(10):1017-28. doi:10.7326/0003-4819-119-10-199311150-00009

9. Stein MD. Medical complications of intravenous drug use. J Gen Intern Med (1990) 5(3):249-57. doi:10.1007/BF02600544

10. Maliphant J, Scott J. Use of the femoral vein ('groin injecting') by a sample of needle exchange clients in Bristol, UK. Harm Reduct J (2005) 2(1):6. doi:10.1186/1477-7517-2-6

11. Darke S, Ross J, Kaye SL. Physical injecting sites among injecting drug users in Sydney, Australia. Drug Alcohol Depend (2001) 62:77-82. doi:10.1016/S03768716(00)00161-7

12. Rafiey H, Narenjiha H, Shirinbayan P, Noori R, Javadipour M, Roshanpajouh M, et al. Needle and syringe sharing among Iranian drug injectors. Harm Reduct $J$ (2009) 6:21. doi:10.1186/1477-7517-6-21

13. Narenjiha H, Rafiey H, Jahani MR, Assari S, Moharamzad Y, Roshanpazooh M. Substance-dependent professional drivers in Iran: a descriptive study. Traffic Inj Prev (2009) 10(3):227-30. doi:10.1080/15389580902849017

14. Razzaghi EM, Rahimi Movaghar A, Hosseini M, Madani S. Rapid Situation Assessment of Drug Abuse in Iran. Tehran: Prevention Department, State Welfare Organization (1999).

15. Berkman L, Kawachi I, editors. Social Epidemiology. New York: Oxford University Press (2000).

16. Blakely T. The New Zealand Census-Mortality Study: Socioeconomic Inequalities and Adult Mortality 1991-94. Wellington: Ministry of Health (2002).

17. Blakely T, Hales S, Kieft C, Wilson N, Woodward A. The global distribution of risk factors by poverty: a complementary CRA. In: Murray C, editor. Comparative Quantification of Health Risks: Global and Regional Burden of Disease Attributable to Selected Major Risk Factors. Geneva: World Health Organization (2004).

18. Blakely T, Pearce N. Socioeconomic position is more than just NZ Dep. NZ Med $J$ (2002) 115:109-11. 
19. Agha A, Parviz S, Younus M, Fatmi Z. Socio-economic and demographic factors associated with injecting drug use among drug users in Karachi, Pakistan. J Pak Med Assoc (2003) 53(11):511-6.

20. Généreux M, Bruneau J, Daniel M. Association between neighbourhood socioeconomic characteristics and high-risk injection behaviour amongst injection drug users living in inner and other city areas in Montréal, Canada. Int J Drug Policy (2010) 21(1):49-55. doi:10.1016/j.drugpo.2009.01.004

21. Fuller CM, Vlahov D, Latkin CA, Ompad DC, Celentano DD, Strathdee SA. Social circumstances of initiation of injection drug use and early shooting gallery attendance: implications for HIV intervention among adolescent and young adult injection drug users. J Acquir Immune Defic Syndr (2003) 32(1):86-93. doi:10.1097/00126334-200301010-00013

22. Altaf A, Ali Shah S, Zaidi NA, Memon A, Nadim-ur-Rehman, Wray N. High risk behaviors of injection drug users registered with harm reduction programme in Karachi, Pakistan. Harm Reduct J (2007) 4:7. doi:10.1186/14777517-4-7

23. Fuller CM, Borrell LN, Latkin CA, Galea S, Ompad DC, Strathdee SA, et al. Effects of race, neighborhood, and social network on age at initiation of injection drug use. Am J Public Health (2005) 95(4):689-95. doi:10.2105/AJPH.2003. 02178

24. Baldwin P, Shrestha R, Potrepka J, Copenhaver M. The age of initiation of drug use and sexual behavior may influence subsequent HIV risk behavior: a systematic review. ISRN AIDS (2013). doi:10.1155/2013/976035

25. Buchmann AF, Schmid B, Blomeyer D, Zimmermann US, Jennen-Steinmetz C, Schmidt $\mathrm{MH}$, et al. Drinking against unpleasant emotions: possible outcome of early onset of alcohol use? Alcohol Clin Exp Res (2010) 34(6):1052-7. doi:10.1111/j.1530-0277.2010.01180.x

26. Squeglia LM, Jacobus J, Tapert SF. The influence of substance use on adolescent brain development. Clin EEG Neurosci (2009) 40(1):31-8. doi:10.1177/ 155005940904000110
27. Woodburn KR, Murie JA. Vascular complications of injecting drug misuse. BrJ Surg (1996) 83(10):1329-34. doi:10.1002/bjs.1800831005

28. Martin CA, Wijesurendra RS, Borland CD, Karas JA. Femoral vein thrombophlebitis and septic pulmonary embolism due to a mixed anaerobic infection including Solobacterium moorei: a case report. J Med Case Reports (2007) 2(1):40. doi:10.1186/1752-1947-1-40

29. Somers WJ, Lowe FC. Localized gangrene of the scrotum and penis: a complication of heroin injection into the femoral vessels. J Urol (1986) 136(1): 111-3.

Conflict of Interest Statement: The authors declare that the research was conducted in the absence of any commercial or financial relationships that could be construed as a potential conflict of interest.

Received: 24 August 2013; paper pending published: 02 September 2013; accepted: 13 February 2014; published online: 07 April 2014.

Citation: Karimi M, Ghaheri H, Assari S, Ahmadi K, Moghani Lankarani M, Moghani Lankarani R, Narenjiha H, Rafiey H, Tavakoli $M$ and Jafari $F$ (2014) Drug injection to sites other than arm: a study of Iranian heroin injectors. Front. Psychiatry 5:23. doi: 10.3389/fpsyt.2014.00023

This article was submitted to Addictive Disorders and Behavioral Dyscontrol, a section of the journal Frontiers in Psychiatry.

Copyright (C) 2014 Karimi, Ghaheri, Assari, Ahmadi, Moghani Lankarani, Moghani Lankarani, Narenjiha, Rafiey, Tavakoli and Jafari. This is an open-access article distributed under the terms of the Creative Commons Attribution License (CC BY). The use, distribution or reproduction in other forums is permitted, provided the original author(s) or licensor are credited and that the original publication in this journal is cited, in accordance with accepted academic practice. No use, distribution or reproduction is permitted which does not comply with these terms. 